\title{
Multimorbidity patterns in old adults and their associated multi-layered factors: a cross-sectional study
}

\author{
Jiao Lu* ${ }^{1 *}$, Yuan Wang ${ }^{1}$, Lihong $\mathrm{Hou}^{2}$, Zhenxing Zuo ${ }^{3}, \mathrm{Na}_{\text {Zhang }}{ }^{1}$ and Anle Wei ${ }^{1}$
}

\begin{abstract}
Background: Influenced by various factors such as socio-demographic characteristics, behavioral lifestyles and socio-cultural environment, the multimorbidity patterns in old adults remain complex. This study aims to identify their characteristics and associated multi-layered factors based on health ecological model.

Methods: In 2019, we surveyed a total of 7480 participants aged $60+$ by using a multi-stage random cluster sampling method in Shanxi province, China. Latent class analysis was used to discriminate the multimorbidity patterns in old adults, and hierarchical regression was performed to determine the multi-layered factors associated with their various multimorbidity patterns.

Results: The prevalence of multimorbidity was $34.70 \%$ among the old patients with chronic disease. Over half (60.59\%) of the patients with multimorbidity had two co-existing chronic diseases. "Degenerative/digestive diseases", "metabolic diseases" and "cardiovascular diseases" were three specific multimorbidity patterns. Behavioral lifestyles-layered factors had the most explanatory power for the three patterns, whose proportions of explanatory power were 54.00, 43.90 and $48.15 \%$ individually. But the contributions of other multi-layered factors were different in different patterns; balanced diet, medication adherence, the size of family and friendship network, and different types of basic medical insurance might have the opposite effect on the three multimorbidity patterns $(p<0.05)$.

Conclusions: In management of old patients with multimorbidity, we should prioritize both the "lifestyle change"centered systematic management strategy and group-customized intervention programs.
\end{abstract}

Keywords: Multimorbidity, Patterns, Health ecological model, Multi-layered factors

\section{Background}

The number of chronic diseases in old patients increases with age, which laid disease burdens to old patients and government $[1,2]$. A study revealed the risk of death was $1.73(95 \%$ CI: $1.41 ; 2.13)$ and $2.72(95 \%$ CI: 1.81 ; 4.08) for individuals with $2+$ and $3+$ co-existing chronic diseases respectively compared with individuals with $\leq 1$ chronic disease [3]. The coexistence of two or more

\footnotetext{
* Correspondence: lujiao801@163.com

1School of Management, Shanxi Medical University, 56 Xinjian South Road, Taiyuan 030001, Shanxi Province, China

Full list of author information is available at the end of the article
}

chronic diseases in the same individual is called as "multimorbidity" [4]. This term originated from "comorbidity" [5] but differed from the conception of "comorbidity" that signified a "distinct additional clinical entity" occurring in the setting of an index disease $[6,7]$. The conception of "multimorbidity" remains humancentered and focuses on exploring the systematic methods of prevention and intervention of the common risk factors. Frailty can also be used to measure the risk profile of old adults in order to support clinical decisions and design tailored interventions. Frailty refers to a medical syndrome with multiple causes and contributors. It

C C The Author(s). 2021 Open Access This article is licensed under a Creative Commons Attribution 4.0 International License, which permits use, sharing, adaptation, distribution and reproduction in any medium or format, as long as you give appropriate credit to the original author(s) and the source, provide a link to the Creative Commons licence, and indicate if changes were made. The images or other third party material in this article are included in the article's Creative Commons licence, unless indicated otherwise in a credit line to the material. If material is not included in the article's Creative Commons licence and your intended use is not permitted by statutory regulation or exceeds the permitted use, you will need to obtain permission directly from the copyright holder. To view a copy of this licence, visit http://creativecommons.org/licenses/by/4.0/ The Creative Commons Public Domain Dedication waiver (http://creativecommons.org/publicdomain/zero/1.0/) applies to the data made available in this article, unless otherwise stated in a credit line to the data. 
is characterized by diminished strength, endurance, and reduced physiologic function that increases an individual's vulnerability for developing increased dependency and/or death [8]. Compared with frailty, multimorbidity has a more recognizable measuring standard and implies a more holistic evaluation of the individual's clinical complexity [9]. To reflect this complexity, it is needed to analyze the differences among co-existing chronic diseases patterns but not the discrepancy in the number of chronic diseases $[10,11]$. Besides, the probability of occurrence through specific patterns was higher than that of random disease combinations among patients with multimorbidity.

Recognition of specific patterns will help clinicians predict the possible occurrence of multimorbidity risks among patients and prevent or intervene those risks at group level [12]. However, due to differences in contextual features (ethnic characteristics, living habits, etc.), multimorbidity patterns in different regions and countries also presented differently [13]. Garin et al. analyzed the data from the Collaborative Research on Ageing in Europe project and the World Health Organization's Study on Global Ageing and Adult Health [14]. They discovered three prevalent multimorbidity patterns around the world, which were "cardio-respiratory" (angina, asthma, and chronic obstructive pulmonary disease), "metabolic" (diabetes, adiposis, and hypertension), and "mental-articular" (arthritis and depression). Sheridan et al. conducted a prospective analysis by using the data from the Survey of Health, Ageing and Retirement in Europe in both 2013 and 2015 [15]. Their results identified 380 unique combinations of chronic disease in old adults with multimorbidity, which proved that hypertension almost existed in each prevalent disease combination. The study of Hernández et al. in Ireland found hypertension and hypercholesterolemia were the most common co-existing diseases by analyzing the chronic diseases combinations from 6101 old adults aged $50+$ [12]. Gu et al. identified three multimorbidity patterns ("degenerative disorders", "digestive/respiratory disorders", and "cardiovascular/metabolic disorders") by analyzing the data of old adults aged $60+$ in Nanjing, China through exploratory factor analysis [16]. Furthermore, some studies discovered that multimorbidity patterns were also influenced by individual characteristics, such as socio-demographic characteristics, behavioral lifestyles and socio-economic factors excepting for contextual features [17-20].

To accurately determine multimorbidity patterns and their risk factors, some studies introduced theories of cognitive psychology as the factor screening basis, but they rarely involved comprehensive context features. For example, Singer et al. assessed the relationships between multimorbidity and material, psycho-social and behavioural factors based on the theories of social determinants of health $(\mathrm{SDoH})$, but ignored the role of social and cultural contexts [21]. These weaknesses led to the incomplete understanding of the different types of factors associated with multimorbidity, which calls on future researchers to establish effective multimorbidity prevention and intervention strategy. As to this point, this study introduces health ecological model by involving individual-, inter-personal-, community-, organization-, government- and other multi-layered factors associated with individual's health [22, 23]. The model, which evolved from an ecological model, shows individuals' health is affected by innate personal characteristics, psychological behavior characteristics, and macro-environmental factors. Health is the result of the interaction of individual characteristics and contextual features $[24,25]$. Thus, in this study, we initially tried to identify multimorbidity patterns in old adults, then analyzed the possible multi-layered factors associated with them based on health ecological model.

\section{Methods \\ Study design and data collection}

We collected data from a cross-sectional questionnairebased study conducted in Shanxi Province by face-toface interview. The questionnaire developed for this study is provided as Additional file 1, and some questions refer to the scales developed by Craig et al. [26], Lubben et al. [27], Sherbourne and Stewart [28], and Yu et al. [29]. We used a multi-stage random cluster sampling involving four steps by random-number table. The sampling procedures were shown in Fig. 1. We enrolled all the old adults aged $60+$ without cognitive impairment living in the selected residential building/villagers' groups. Also, in order to ensure the authenticity of the investigation, only old adults who held medical certificates (such as medical records) or current prescriptions could be classified as patients with chronic disease. A total of 7480 urban and rural old adults were surveyed, 932 invalid questionnaires were eliminated, and the effective recovery rate was $87.54 \%$. Before the investigation, all investigators were trained in a centralized manner to ensure that they could exactly understand the standards and procedures of the investigation.

\section{Variables}

\section{Outcome variable}

To ensure that multimorbidity patterns could be classified effectively, we primarily assessed what kind of chronic diseases should be included in this survey. Some scholars covered both common and uncommon chronic diseases in their survey to guarantee the completeness of investigation, but researchers found that this just increased the complexity of the evaluation but decreased 
Shanxi Province administers 11 prefecture-level cities

\begin{tabular}{|l|l|}
\hline 22 county-level administrative units were selected \\
\hline 44 communities (or administrative villages) were selected \\
\hline \begin{tabular}{|l|}
2 communities (or administrative villages) were randomly \\
selected from each county-level administrative unit
\end{tabular} \\
\hline 88 residential buildings (or villager groups) were selected \\
\hline selected from each community (or administrative village) \\
\hline 7,480 old adults aged $60+$ were surveyed \\
\hline
\end{tabular}

the accuracy of the results [30]. By default, at least 12 kinds of chronic diseases could meet the basic requirement of the investigation on quantity, and they should be determined on their regional prevalence [31]. Therefore, we defined 17 chronic diseases in this study, according to the prevalence of chronic diseases of health statistics yearbook in China (2019) [32], the results of the investigation about the prevalence of chronic diseases in Shanxi Province [33], and the suggestions of clinicians. They were adiposis, hypertension, diabetes, coronary heart disease, stroke, arrhythmia, atherosclerosis, bronchial asthma, chronic obstructive pneumonia diseases, sciatica, arthritis, thyroid diseases, osteoporosis, hearing loss, eye diseases, mental diseases, digestive system diseases and others (the summary of all uncommon chronic diseases). Next, we chose the old adults with two or more co-existing diseases to perform an exploratory latent class analysis (LCA), then clustered them into different latent class groups based on the definition of 17 chronic diseases. The result would be used as the observation category variables for subsequent analysis.

\section{Independent variable}

By the comprehensive and systemic literature review of multimorbidity, the factors which influenced the old adults with multimorbidity were integrated in all multilayered of health ecological model in this study (Fig. 2). The variable assignments and measurement scales are shown in Table 1.

\section{Statistical analyses}

The data was input and checked by EpiData3.1, and the diseases status of old adults with multimorbidity was described by the number of diseases $(\mathrm{N})$ and percentage (\%). Meanwhile, LCA was used to identify the multimorbidity patterns, and hierarchical logistic regression analysis was applied to determine the multi-layered factors associated with various multimorbidity patterns for old adults. Specifically, multi-layered predictors were tested step-by-step for their prediction of the outcome variables, and five models were established in each multimorbidity pattern respectively: model I incorporated the first-layer factor (innate personal traits); the second-layer factor (behavioral lifestyles) was added in model II on the basis of the model I; similarly, model III, model IV and $\mathrm{V}$ introduced the third-layer factor (interpersonal networks), the forth-layer factor (socio-economic status) and the fifth-layer factor (macro-environmental) individually on the basis of model II, model III and model IV. We applied Mplus 7.4 to perform LCA and Stata15.1 


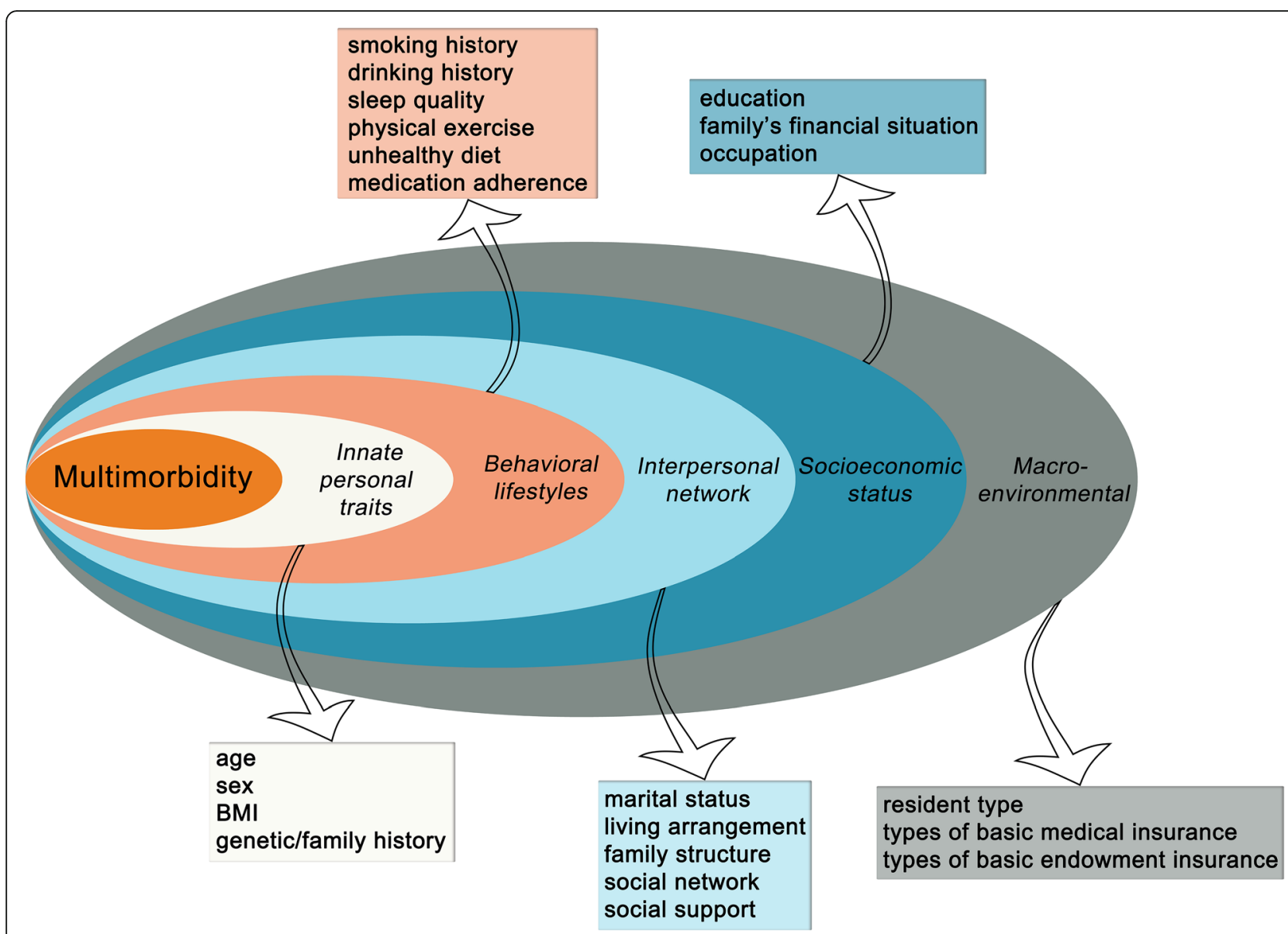

Fig. 2 Health ecological model

to perform hierarchical logistic regression analysis, and statistically significant level was set at 0.05 .

\section{Results}

\section{Descriptive results}

In total, 1188 (18.14\%) old adults did not suffer from any chronic disease, and $34.70 \%$ of patients with chronic disease suffered from multimorbidity. The mean age of 1860 old adults with multimorbidity was $(70.79 \pm 6.954)$ year-old. The majority of multimorbidity old patients suffered from two co-existing chronic diseases (60.59\%).

At the same time, 6 cluster models were extracted in this study by using LCA. From Table 2, by comparing the Bayesian Information Criterion (BIC), the $p$-value of the Bootstrap Likelihood Ratio Test (BLRT) and the interpretability of each class model, the 3-class model was chosen as the optimal one [34]. Moreover, the average probability (column) of the old patients (rows) in multimorbidity of each class ranged from 80.3 to $91.4 \%$ in the 3 -class model (Table 3), and it also showed the credibility of the 3-class model. The response probability graph of the 3-class (Fig. 3) presents multimorbidity old patients in the pattern-I had higher probability of suffering from arthritis, hearing loss, osteoporosis, and digestive system disease, and lower probability of suffering from hypertension, which could be named as "degenerative/ digestive diseases"; those in the pattern-II had nearly $100 \%$ probability of suffering from diabetes and were also vulnerable to get hypertension, which could be called as "metabolic disease"; the prevalence of hypertension in the pattern-III was close to $100 \%$, and even there was about $20 \%$ probability of coronary heart disease, which could be named as "cardiovascular disease". The proportions of these three multimorbidity patterns were $40.86,22.96$ and $36.18 \%$ respectively.

\section{Sensitivity analysis}

Provided that patients with uncommon chronic diseases were also recruited as our respondents, the accuracy of the multimorbidity patterns may be affected. Thus, to assess the reliability of those patterns, we re-selected samples by excluding those individuals belonging to the 'others' category to conduct a sensitivity analysis. We used the LCA to analysis the data of 1581 multimorbidity patients suffering from these 17 common chronic diseases. The results also identified three specific 
Table 1 Assignments and measurement scales of independent variables $(N=1860)$

\begin{tabular}{|c|c|c|c|c|}
\hline Layer factors & Independent variables & Assignments & N (\%) & Mean \pm SD \\
\hline \multirow{4}{*}{ Innate personal trait } & Age & age (years) & & $70.79 \pm 6.954$ \\
\hline & Sex & female, male & $973(52.3) / 887(47.7)$ & \\
\hline & BMI & height/weight2 (kg/m) & & $23.05 \pm 3.677$ \\
\hline & Genetic/family history & no, yes & $1676(90.1) / 184(9.9)$ & \\
\hline \multirow{10}{*}{$\begin{array}{l}\text { "I } \\
\text { Behavioral lifestyle }\end{array}$} & Smoking history & current, quit, never & $297(16.0) / 232(12.5) / 1331(71.6)$ & \\
\hline & Drinking history & current, quit, never & $308(16.6) / 167(9.0) / 1385(74.5)$ & \\
\hline & Sleep quality & very good, good, poor, very poor & $\begin{array}{l}487(26.2) / 981(52.7) / 338(18.2) / \\
54(2.9)\end{array}$ & \\
\hline & Physical exercise & low level, moderate level, high level & 1792(96.3) / 68(3.7) & \\
\hline & Balanced diet & no, yes & $930(50.0) / 930(50.0)$ & \\
\hline & Light diet & no, yes & $702(37.7) / 1158(62.3)$ & \\
\hline & Regular meals & no, yes & $477(25.6) / 1383(74.4)$ & \\
\hline & $\begin{array}{l}\text { Consumption of coarse } \\
\text { cereals }(\mathrm{g})\end{array}$ & $0-100,101-200,201-300,301-400,401-$ & $\begin{array}{l}63(3.4) / 224(12.0) / 415(22.3) / \\
731(39.3) / 427(23.0)\end{array}$ & \\
\hline & $\begin{array}{l}\text { Consumption of fruits } \\
\text { and vegetables }(\mathrm{g})\end{array}$ & $0-100,101-200,201-300,301-400,401-$ & $\begin{array}{l}39(2.1) / 154(8.3) / 243(13.1) / \\
622(33.4) / 802(43.1)\end{array}$ & \\
\hline & Medication adherence & $0-8$ & & $4.30 \pm 2.838$ \\
\hline \multirow{6}{*}{$\begin{array}{l}\text { III } \\
\text { Interpersonal } \\
\text { network }\end{array}$} & Marital status & married, unmarried, divorced, widowed & $\begin{array}{l}24(1.3) / 1413(76.0) / 17(0.9) / \\
406(21.8)\end{array}$ & \\
\hline & Living arrangement & live alone, live with others & 268(14.4) / 1592(85.6) & \\
\hline & Family structure & empty-nest, non-empty-nest & $892(48.0) / 968(52.0)$ & \\
\hline & Family network & LSNS-6 Family subscale & & $12.02 \pm 2.893$ \\
\hline & Friendship network & LSNS-6 Friends subscale & & $8.70 \pm 4.208$ \\
\hline & Social support & MOS-SSS-C & & $71.79 \pm 14.408$ \\
\hline \multirow{3}{*}{$\begin{array}{l}\text { IV } \\
\text { Socio-economic } \\
\text { status }\end{array}$} & Education & $\begin{array}{l}\text { primary school and below, junior school, } \\
\text { high school and above }\end{array}$ & $905(48.7) / 509(27.4) / 446(24.0)$ & \\
\hline & $\begin{array}{l}\text { Per capita monthly family } \\
\text { income (¥) }\end{array}$ & $\leq 1000,1001-3000,3001-5000,>5000$ & $\begin{array}{l}712(38.3) / 614(33.0) / 422(22.7) / \\
112(6.0)\end{array}$ & \\
\hline & Pre-retirement occupation & $\begin{array}{l}\text { public functionary, farmer, self-employed, } \\
\text { unemployed, others }\end{array}$ & $\begin{array}{l}585(31.5) / 775(41.7) / 167(9.0) / \\
85(4.6) / 248(13.3)\end{array}$ & \\
\hline \multirow{3}{*}{$\begin{array}{l}\text { V } \\
\text { Macro-environmental }\end{array}$} & Resident type & rural, urban & $982(52.8) / 878(47.2)$ & \\
\hline & $\begin{array}{l}\text { Types of basic medical } \\
\text { insurance }\end{array}$ & $\begin{array}{l}\text { urban employee basic medical insurance, } \\
\text { urban and rural resident medical } \\
\text { insurance, others }\end{array}$ & $558(30.0) / 1138(61.2) / 164(8.8)$ & \\
\hline & $\begin{array}{l}\text { Types of basic endowment } \\
\text { insurance }\end{array}$ & $\begin{array}{l}\text { urban employee basic endowment } \\
\text { insurance, urban and rural resident } \\
\text { endowment insurance, others }\end{array}$ & $475(25.5) / 1326(71.3) / 59(3.2)$ & \\
\hline
\end{tabular}

Table 2 Model-fit statistics comparison for latent class analysis

\begin{tabular}{llllllll}
\hline Model & $\mathbf{k}$ & AIC & BIC & aBIC & Entropy & LMR & BLRT \\
\hline 1 Class & 17 & $21,073.821$ & $21,167.803$ & $21,113.794$ & - & - & $<$ \\
2 Classes & 35 & $20,627.163$ & $20,820.654$ & $20,709.460$ & 0.485 & $<.0001$ & $<.0001$ \\
3 Classes & 53 & $20,525.961$ & $20,818.962$ & $20,650.582$ & 0.729 & $<.0001$ & $<.0001$ \\
4 Classes & 71 & $20,468.246$ & $20,860.758$ & $20,635.192$ & 0.793 & 0.4490 & $<.0001$ \\
5 Classes & 89 & $20,413.296$ & $20,905.317$ & $20,622.566$ & 0.857 & 0.0009 & $<.0001$ \\
6 Classes & 107 & $20,382.435$ & $20,973.967$ & $20,634.030$ & 0.868 & 0.9101 & $<.0001$
\end{tabular}

k Number of Free Parameters, AIC Akaike Information Criterion, BIC Bayesian Information Criterion, aBIC Adjusted Bayesian Information Criterion, LMR Lo-MendellRubin Likelihood Ratio Test, BLRT Bootstrap Likelihood Ratio Test 
Table 3 The average probability (column) of the old patients (rows) in multimorbidity of each class

\begin{tabular}{llll}
\hline & Class 1 (\%) & Class 2 (\%) & Class 3 (\%) \\
\hline Class 1 & 91.4 & 2.6 & 6.0 \\
Class 2 & 8.6 & 91.4 & 0.0 \\
Class 3 & 19.7 & 0.0 & 80.3 \\
\hline
\end{tabular}

multimorbidity patterns: "degenerative/digestive diseases", "metabolic diseases" and "cardiovascular diseases"; and that was similar to the original ones. More detailed information is included in Additional file 2.

\section{Hierarchical regression analysis results}

The results showed that the degree of interpretation of the model could continuously rise with the addition of multi-layered factors; the behavioral lifestyles-layered factors explained the most for the three patterns, and their proportions of explanatory power were 54.00, 43.90 and $48.15 \%$ individually. But specific factors in multilayered associated with three multimorbidity patterns were significantly different (Table 4).
Regarding the "degenerative/digestive diseases" pattern, the factors in innate personal traits layer failed to significantly predict the "degenerative/digestive diseases" but other layers could predict it. The probability of getting "degenerative/digestive diseases" may rise in patients with very poor sleep quality, an imbalanced diet, great size of the family network and upper-middleincome (¥3001-5000). Factors such as good medication adherence, great scale of friendship network, high social support and participation in urban employee basic medical insurance (UEBMI) and urban and rural resident medical insurance (URRMI) might reduce the probability of this disease pattern.

With regard to the "metabolic diseases" pattern, five multi-layered factors were all predicted significantly. The genetic/family history, good medication adherence, great size of friendship network and participation in the UEBMI and URRMI, were risk factors for "metabolic diseases" pattern. However, an imbalanced diet, the extension of the family network's size, and junior school education were protective factors for this pattern.

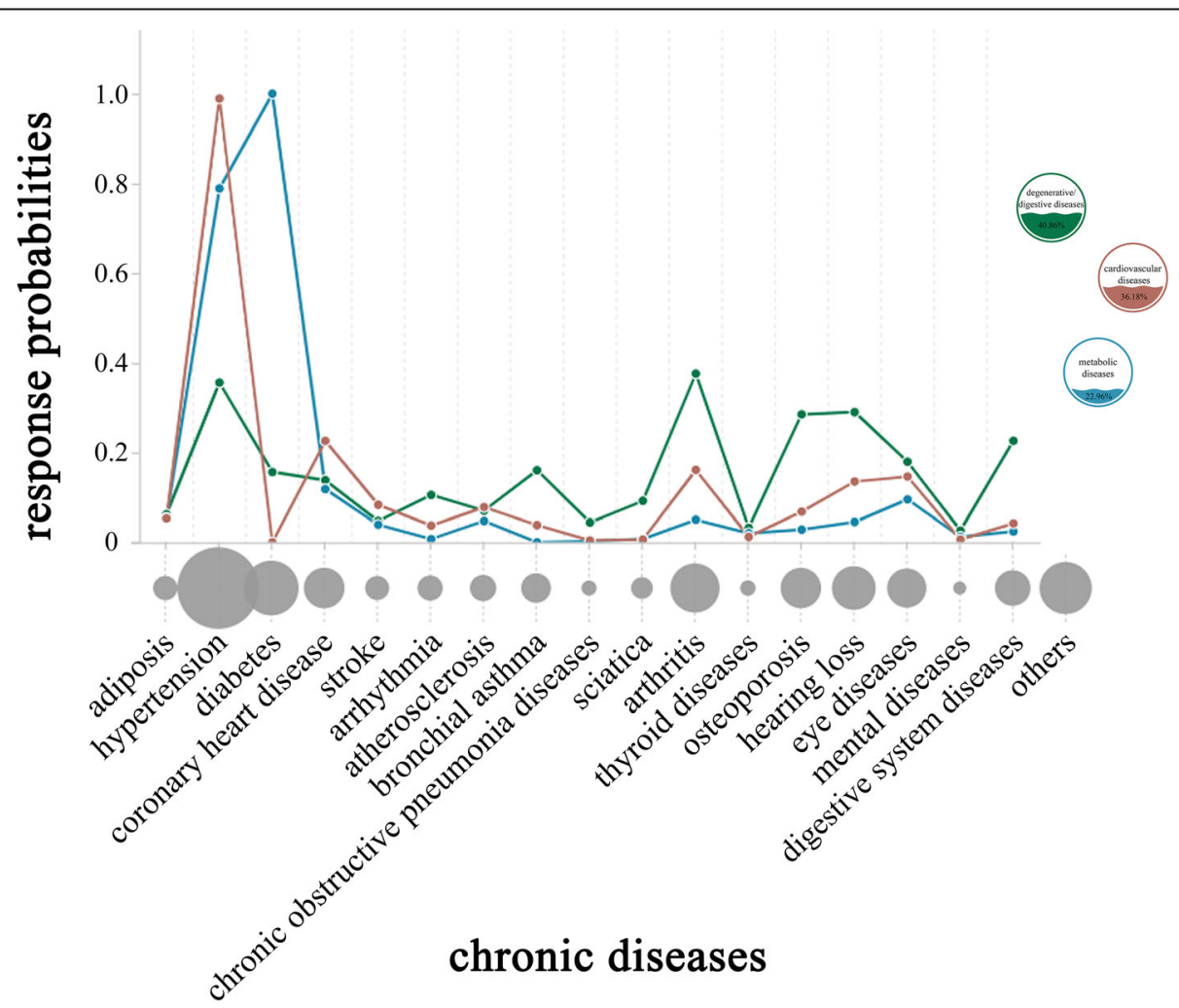

Fig. 3 A combined figure. The gray bubbles on the horizontal axis represent the prevalence of each disease in patients with multimorbidity, and the line graph on the vertical axis represents the observation items of each potential class in the results of the LCA, that is, the response probability of 17 chronic diseases. The bubble size in the legend indicates the proportion of the three multimorbidity patterns. The green bubble and line graph depict the data of "degenerative/digestive diseases", the brown bubble and line graph describe the data of "cardiovascular diseases", and the blue bubble and line graph delineate the "metabolic diseases" 
Table 4 Hierarchical regression analysis of the factors associated with multimorbidity patterns

\begin{tabular}{|c|c|c|c|c|}
\hline \multirow[t]{2}{*}{ Layer factors } & \multirow[t]{2}{*}{ Independent variables } & \multicolumn{3}{|l|}{ OR } \\
\hline & & Pattern 1 & Pattern 2 & Pattern 3 \\
\hline \multirow{4}{*}{$\begin{array}{l}\text { Innate personal trait } \\
\text { । }\end{array}$} & Age & - & - & $1.02^{* *}$ \\
\hline & Genetic/family history & & & \\
\hline & no & & Reference & \\
\hline & yes & - & $1.67^{* * *}$ & - \\
\hline \multirow{16}{*}{$\begin{array}{l}\text { II } \\
\text { Behavioral lifestyle }\end{array}$} & Sleep quality & & & \\
\hline & very good & & Reference & \\
\hline & good & - & - & - \\
\hline & poor & - & - & - \\
\hline & very poor & $1.97^{* *}$ & - & - \\
\hline & Physical exercise & & & \\
\hline & low level & - & - & - \\
\hline & moderate level & & Reference & \\
\hline & high level & - & - & $0.15^{* *}$ \\
\hline & Balanced diet & & & \\
\hline & no & $1.40^{* * *}$ & $0.70^{* * *}$ & - \\
\hline & yes & & Reference & \\
\hline & Light diet & & & \\
\hline & no & - & - & $1.28^{* *}$ \\
\hline & yes & & Reference & \\
\hline & Medication adherence & $0.92^{* * *}$ & $1.05^{* *}$ & $1.05^{* * *}$ \\
\hline \multirow{3}{*}{$\begin{array}{l}\text { III } \\
\text { Interpersonal network }\end{array}$} & Family network & $1.07^{* * *}$ & $0.94^{* * *}$ & - \\
\hline & Friendship network & $0.97^{* *}$ & $1.03^{* *}$ & - \\
\hline & Social support & $0.99^{* *}$ & - & - \\
\hline \multirow{9}{*}{$\begin{array}{l}\text { IV } \\
\text { Socio-economic status }\end{array}$} & Education & & & \\
\hline & primary school and below & & Reference & \\
\hline & junior school & - & $0.69^{* *}$ & - \\
\hline & high school and above & - & - & - \\
\hline & Per capita monthly family income ( $¥)$ & & & \\
\hline & $0-1000$ & & Reference & \\
\hline & $1001-3000$ & - & - & - \\
\hline & $3001-5000$ & $1.56^{* *}$ & - & - \\
\hline & $5001-$ & - & - & - \\
\hline \multirow{4}{*}{$\begin{array}{l}\text { V } \\
\text { Macro-environmental }\end{array}$} & Types of basic medical insurance & & & \\
\hline & urban employee basic medical insurance & $0.49^{* * *}$ & $2.58^{* * *}$ & - \\
\hline & urban and rural resident medical insurance & $0.66^{* *}$ & $1.88^{* *}$ & - \\
\hline & others & & Reference & \\
\hline
\end{tabular}

Note. Only significant variables are shown here. Standard errors are in parenthesis ${ }^{* *} p<0.01,{ }^{* *} p<0.05$

As to the "cardiovascular diseases" pattern, only innate personal traits-layered factor and behavioral lifestyleslayered factor significantly predicted the "cardiovascular diseases". Aging, heavy oil and high-salt diet and good medication adherence, might rise the probability of patients suffering from "cardiovascular diseases"; while highintensity physical exercise might significantly reduce it.

\section{Discussion}

We identified "degenerative/digestive diseases", "metabolic diseases" and "cardiovascular diseases" as the three specific patterns of multimorbidity among Chinese old patients with chronic disease in this study. The pattern of degenerative/digestive diseases is comprised of similar proportions of arthritis, hypertension, hearing loss, 
osteoporosis, digestive system diseases, eye diseases, and its prevalence was $40.86 \%$. Degenerative diseases as a separate pattern were observed in Chinese old populations but not in other countries or regions [16, 35-40]. $\mathrm{Gu}$ et al. used data from the community-dwelling old persons in Nanjing, China and discovered hearing disorder, cataract, joint disease and cancer were included in the degenerative diseases group [16, 38], but cancer was not included in our and other studies [35-37, 39]. Meanwhile, the digestive system diseases and arthritis diseases were often clustered (stomach or other digestive disease, arthritis) among older Chinese [40, 41]. Moreover, the patterns of cardiovascular diseases and metabolic diseases were observed in almost all studies focusing on older Chinese [16, 38, 39, 41, 42]. In this study, the pattern of metabolic diseases was characterized by having $100 \%$ probability to suffer from diabetes and $78.9 \%$ probability of being ill with hypertension, and its prevalence was $22.96 \%$. While more than 1 in 5 persons in the pattern of cardiovascular diseases had coronary heart-hypertension combination, and the prevalence of this pattern was $36.18 \%$. The study of She et al. found that the pattern of cardiovascular disorders (arrhythmia, ischemic heart disease, and heart failure) and the pattern of metabolic disorders (hypertension, obesity, diabetes, and dyslipidemia) were identified by the 1497 rural community older from the Confucius Hometown Aging Project (2014-2016) in Qufu, Shandong, China [39]. Hypertension, diabetes, coronary heart disease were also the major diseases of the cardiovascular and metabolic diseases patterns in other studies [16, 38, 41]. However, mental illness did not appear in disease combination in this study. This finding was inconsistent with some previous studies. Garin et al. observed a "Mental-articular" pattern in China, Ghana and India, which included arthritis and depression and "Mental-articular" pattern in Spain, which included arthritis, depression and anxiety $[14,43]$. This may be limited by the sample size. The small sample size of mental illnesses leads to the low joint probability and conditional probability of mental illnesses and other chronic diseases [34], resulting in a low probability of mental illnesses appearing in the multimorbidity patterns in our study.

Remarkable heterogeneity in the number, types, and assessment approaches of chronic conditions [39], as well as the aging characteristics of different study samples [16], has led to some differences in the combination of patterns across studies, but specific common multimorbidity patterns have been identified, such as metabolic syndromes, degenerative and cardiovascular diseases.

What's more interesting, some specific multi-layered factors were protective factors for one pattern, but risk factors for another. An imbalanced diet might cause gastrointestinal mucosal damage and dysfunction which might increase the incidence of "degenerative/digestive diseases". While, "metabolic diseases" always require an accurate and strict restriction on the intake of foods rich in fats, protein, starch and sugar, so a reasonable diet might increase the probability of this disease. A great scale and close-contact of friendship network might enhance the patients' mutual assistance and information exchange in chronic disease management to reduce the incidence of such "degenerative/digestive diseases" pattern $[21,44,45]$. But individuals may be opposed to disease management because of the negative emotions brought about by excessive constraints from family members. Some unreasonable lifestyle habits might be aggrandized with the expansion of the friendship network which increase the incidence of "metabolic diseases" pattern. It is worth mentioning that good medication adherence might no longer be beneficial for all disease patterns. In the early stages of disease, rational administration might prevent functional injuries and reduce the incidence of "degenerative/digestive diseases". However, long-term use of certain drugs would lead to the "metabolic diseases" pattern [46]. For example, long-term use of atypical antipsychotic drugs (AAP) might increase the risk of weight gain, blood sugar and blood lipids rise and insulin resistance, which would lead to adiposis, diabetes, high blood pressure, etc. [47]. In addition, medication adherence might also increase the risk of "cardiovascular diseases" in multimorbidity patients. Ferdinandy et al. discovered that some comorbidities and their medications might have potential cardiotoxity of a drug [48]. Medication is the preferred way to control disease progression, but to avoid adverse drug interactions that further complicate the disease, we should pay attention to the adverse effects of long-term medication on certain multimorbidity patterns. In addition, except for the factors above, genetic/family history might increase the risk of "metabolic diseases" $[49,50]$. Aging and heavy oil and high-salt diet were the risk factors for "cardiovascular disease" [51, 52], while high-intensity physical exercise was a protective factor [53].

There were four limitations in this study. First, crosssectional data in this study failed to consider the time effect on multimorbidity, and the causality inference could not be estimated. Meanwhile, although our investigators were strictly trained and had medical professional backgrounds, self-reported variables in our study also may be misestimated inevitably. A large-scale longitudinal study should be designed to validate these possible causal hypotheses in future more accurately. Second, the data in this study were investigated from a single geographical region, which might be difficult to verify the effect of macro-environmental factors effectively. Thus, the conclusion of this study should be applicable to regions with 
the same political and cultural environment. Future studies should expand the research area to the whole China or even more countries. Third, the proportion of old adults with multimorbidity may be underestimated because respondents who have suffered from chronic illnesses but not diagnosed by doctors may be excluded in our study. Moreover, although most Chinese older people choose home-based care, the chronically ill older people who lived in nursing homes or hospitals were not interviewed. Fourth, the variables involved in this study might not be comprehensive enough to cover all associated factors, although these variables were selected based on health ecological model and systemic literature review. Some other variables such as home and community living environment should be further analyzed in future studies.

\section{Conclusions}

In this study, we identified three specific multimorbidity patterns, "degenerative/digestive diseases", "metabolic diseases" and "cardiovascular diseases", among old Chinese patients. The behavioral lifestyles-layered factors mostly explained three multimorbidity patterns, but specific factors of different layers in the three multimorbidity patterns were significantly different, and some factors might even have opposite effects on different multimorbidity patterns. Therefore, a multi-level "individual-community-government" systematic management strategy should be established to manage old patients' multimorbidity, considering both the "lifestyle change"-centered systematic management strategy and group-customized intervention program for different multimorbidity patterns. From the perspective of individuals, the selfmanagement ability of old patients with chronic diseases should be improved in continuous visualized education and decision-making to provide more support in healthpromotion and disease-prevention behaviors. From the perspective of communities, the multimorbidity care service delivery system should be strengthened by firstly building a knowledge-sharing network to facilitate the peer effect of patient group with multimorbidity, and by secondly establishing classified and graded archives and remote dynamic risk monitoring and early warning system for multimorbidity patients to help formulate group-customized intervention programs. From the perspective of the government, a unified and coordinated two-way referral tactics should be developed to improve the management of multimorbidity, and give full play to the catch-all and mutual-aid roles of basic medical insurance.

\section{Abbreviations}

LCA: Latent class analysis; BIC: Bayesian Information Criterion; BLRT: Bootstrap Likelihood Ratio Test; AAP: Atypical antipsychotic drugs; SDoH: Theories of social determinants of health; UEBMI: Urban employee basic medical insurance; URRMI: Urban and rural resident medical insurance

\section{Supplementary Information}

The online version contains supplementary material available at https://doi. org/10.1186/s12877-021-02292-w.

Additional file 1. Questionnaire for old adults

Additional file 2. Sensitivity analysis

\section{Acknowledgements}

We would like to give thanks to all members from investigation team of 11 'behavioral decision and health management' in Shanxi Medical University, and all older patients who accepted to join this project.

\section{Authors' contributions}

Conceptualization: JL. Methodology: JL, YW. Formal analysis and investigation: JL, YW, LH, ZZ, NZ. Writing - original draft preparation: JL, YW, AW. Writing - review and editing: JL, YW, ZZ. Funding acquisition: JL. Supervision: LH, NZ. Validation: ZZ. All authors read and approved the final manuscript.

\section{Funding}

This study was funded by the National Natural Science Foundation of China (No. 71804101), Soft Science Research Program in Shanxi Province (No. 2018041037-2), General Project of Shanxi Province University Philosophy and Social Science (No. 201803064), the Doctorial Start-up Fund of Shanxi Medical University (No. BS201738), Key research base of philosophy and social sciences in Shaanxi Province-Health Culture Research Center of Shaanxi (No. JKWH2019-Q10), and Scientific and technological innovation projects of colleges and universities in Shanxi Province (No. 2019L0446). The funding body was not involved in the design of the study, the collection, analysis, or interpretation of the data, or in writing the manuscript.

\section{Availability of data and materials}

The datasets generated and analyzed during the current study are available from the corresponding author on reasonable request.

\section{Declarations}

Ethics approval and consent to participate

Approval was obtained from the Ethics Committee of Shanxi Medical University. The judgement's number was 2018LL232. The procedures used in this study adhere to the tenets of the Declaration of Helsinki. Written informed consent was obtained from all individual participants included in the study.

Consent for publication

Not applicable.

\section{Competing interests}

The authors declare that they have no competing interests.

\section{Author details}

${ }^{1}$ School of Management, Shanxi Medical University, 56 Xinjian South Road, Taiyuan 030001, Shanxi Province, China. ${ }^{2}$ The Second Affiliated Hospital, Shaanxi University of Chinese Medicine, Xianyang, Shaanxi Province, China. ${ }^{3}$ School of Public Health, Shanxi Medical University, Taiyuan, Shanxi Province, China.

Received: 28 August 2020 Accepted: 20 May 2021

Published online: 19 June 2021

\section{References}

1. Prazeres F, Santiago L. Prevalence of multimorbidity in the adult population attending primary care in Portugal: a cross-sectional study. BMJ Open. 2015; 5(9):e009287. https://doi.org/10.1136/bmjopen-2015-009287.

2. Ofori-Asenso R, Chin KL, Curtis AJ, Zomer E, Zoungas S, Liew D. Recent patterns of multimorbidity among older adults in high-income countries. 
Popul Health Manag. 2019;22(2):127-37. https://doi.org/10.1089/pop.2018. 0069.

3. Nunes BP, Flores TR, Mielke GI, Thumé E, Facchini LA. Multimorbidity and mortality in older adults: a systematic review and meta-analysis. Arch Gerontol Geriatr. 2016;67:130-8. https://doi.org/10.1016/j.archger.2016.07.008.

4. Van den Akker M, Buntix F, Knottnerus JA. Comorbidity or multimorbidity: what's in a name? A review of literature. Eur J Gen Pract. 1996;2(2):65-70. https://doi.org/10.3109/13814789609162146.

5. Salisbury C. Multimorbidity: redesigning health care for people who use it. Lancet. 2012;380(9836):7-9. https://doi.org/10.1016/S0140-6736(12)60482-6.

6. Feinstein AR. The pre-therapeutic classification of comorbidity in chronic disease. J Chronic Dis. 1970;23(7):455-68. https://doi.org/10.1016/0021-9681 (70)90054-8.

7. Kraemer HC. Statistical issues in assessing comorbidity. Stat Med. 1995;14(8): 721-3. https://doi.org/10.1002/sim.4780140803.

8. Morley JE, Vellas B, van Kan GA, Anker SD, Bauer JM, Bernabei R, et al. Frailty consensus: a call to action. J Am Med Dir Assoc. 2013;14(6):392-7. https:// doi.org/10.1016/j.jamda.2013.03.022

9. Cesari M, Pérez-Zepeda MU, Marzetti E. Frailty and multimorbidity: different ways of thinking about geriatrics. J Am Med Dir Assoc. 2017;18(4):361-4. https://doi.org/10.1016/j.jamda.2016.12.086.

10. Kshatri JS, Palo SK, Bhoi T, Barik SR, Pati S. Prevalence and patterns of multimorbidity among rural elderly: findings of the AHSETS study. Front Public Health. 2020;8:582663. https://doi.org/10.3389/fpubh.2020.582663.

11. Kim J, Keshavjee S, Atun R. Trends, patterns and health consequences of multimorbidity among South Korea adults: analysis of nationally representative survey data 2007-2016. J Glob Health. 2020;10(2):020426. https://doi.org/10.7189/jogh.10.020426.

12. Hernandez B, Reilly RB, Kenny RA. Investigation of multimorbidity and prevalent disease combinations in older lrish adults using network analysis and association rules. Sci Rep. 2019;9(1):14567. https://doi.org/10.1038/s41 598-019-51135-7.

13. Mondor L, Cohen D, Khan Al, Wodchis WP. Income inequalities in multimorbidity prevalence in Ontario, Canada: a decomposition analysis of linked survey and health administrative data. Int J Equity Health. 2018;17(1): 90. https://doi.org/10.1186/s12939-018-0800-6.

14. Garin N, Koyanagi A, Chatterji S, Tyrovolas S, Olaya B, Leonardi M, et al. Global multimorbidity patterns: a cross-sectional, population-based, multicountry study. J Gerontol A Biol Sci Med Sci. 2016;71(2):205-14. https://doi. org/10.1093/gerona/glv128.

15. Sheridan PE, Mair CA, Quinones AR. Associations between prevalent multimorbidity combinations and prospective disability and self-rated health among older adults in Europe. BMC Geriatr. 2019;19(1):198. https:// doi.org/10.1186/s12877-019-1214-z.

16. Gu J, Chao J, Chen W, Xu H, Zhang R, He T, et al. Multimorbidity and health-related quality of life among the community-dwelling elderly: a longitudinal study. Arch Gerontol Geriatr. 2018;74:133-40. https://doi.org/1 0.1016/j.archger.2017.10.019.

17. Wang SB, D'Arcy C, Yu YQ, Li B, Liu YW, Tao YC, et al. Prevalence and patterns of multimorbidity in northeastern China: a cross-sectional study. Public Health. 2015;129(11):1539-46. https://doi.org/10.1016/j.puhe.2015.06.013.

18. Ahmadi B, Alimohammadian $M$, Yaseri M, Majidi A, Boreiri M, Islami F, et al. Multimorbidity: epidemiology and risk factors in the Golestan cohort study, Iran. Medicine. 2016;95(7):e2756. https://doi.org/10.1097/MD.0000000000002 756.

19. Katikireddi SV, Skivington K, Leyland AH, Hunt K, Mercer SW. The contribution of risk factors to socioeconomic inequalities in multimorbidity across the lifecourse: a longitudinal analysis of the Twenty-07 cohort. BMC Med. 2017;15(1):152. https://doi.org/10.1186/s12916-017-0913-6.

20. Ashworth M, Durbaba S, Whitney D, Crompton J, Wright M, Dodhia H. Journey to multimorbidity: Iongitudinal analysis exploring cardiovascular risk factors and sociodemographic determinants in an urban setting. BMJ Open. 2019;9(12):e031649. https://doi.org/10.1136/bmjopen-2019-031649.

21. Singer $L$, Green M, Rowe F, Ben-Shlomo Y, Morrissey K. Social determinants of multimorbidity and multiple functional limitations among the ageing population of England, 2002-2015. SSM-Population Health. 2019;8:100413. https://doi.org/10.1016/.jssmph.2019.100413.

22. Robinson T. Applying the socio-ecological model to improving fruit and vegetable intake among low-income African Americans. J Community Health. 2008:33(6):395-406. https://doi.org/10.1007/s10900-008-9109-5.
23. Sallis JF, Owen N, Fisher EB. In: Glanz K, Rimer BK, Viswanath K, editors Ecological models of health behavior. In: Health behavior and health education: theory, research and practice. 4th ed. San Francisco: Jossey-Bass Inc.; 2008. p. 465-85.

24. McLeroy KR, Bibeau D, Steckler A, Glanz K. An ecological per spective on health promotion programs. Health Educ Q. 1988;15(4):351-77. https://doi. org/10.1177/109019818801500401.

25. Rapport DJ, Howard J, Lannigan R, McCauley W. Linking health and ecology in the medical curriculum. Environ Int. 2003;29(2-3):353-8. https://doi.org/1 0.1016/50160-4120(02)00169-1.

26. Craig CL, Marshall AL, Sjöström M, Bauman AE, Booth ML, Ainsworth BE, et al. International physical activity questionnaire: 12-country reliability and validity. Med Sci Sports Exerc. 2003;35(8):1381-95. https://doi.org/10.1249/01. MSS.0000078924.61453.FB.

27. Lubben J, Blozik E, Gillmann G, lliffe S, von Renteln KW, Beck JC, et al. Performance of an abbreviated version of the Lubben social network scale among three European community-dwelling older adult populations. Gerontologist. 2006;46(4):503-13. https://doi.org/10.1093/geront/46.4.503.

28. Sherbourne CD, Stewart AL. The MOS social support survey. Soc Sci Med. 1991;32(6):705-14. https://doi.org/10.1016/0277-9536(91)90150-B.

29. Yu DS, Lee DT, Woo J. Psychometric testing of the Chinese version of the medical outcomes study social support survey (MOS-SSS-C). Res Nurs Health. 2004;27(2):135-43. https://doi.org/10.1002/nur.20008.

30. Sakib MN, Shooshtari S, St John P, Menec V. The prevalence of multimorbidity and associations with lifestyle factors among middle-aged Canadians: an analysis of Canadian longitudinal study on aging data. BMC Public Health. 2019;19(1):243. https://doi.org/10.1186/s12889-019-6567-x.

31. Fortin M, Stewart M, Poitras ME, Almirall J, Maddocks H. A systematic review of prevalence studies on multimorbidity: toward a more uniform methodology. Ann Fam Med. 2012;10(2):142-51. https://doi.org/10.1370/a fm. 1337 .

32. National Health Commission of the People's Republic of China. Chinese health statistics yearbook of 2019. Beijing: Peking Union Medical College Press; 2019. (In Chinese)

33. Zhou M, Wang H, Zeng X, Yin P, Zhu J, Chen W, et al. Mortality, morbidity, and risk factors in China and its provinces, 1990-2017: a systematic analysis for the global burden of disease study 2017. Lancet. 2019;394(10204):114558. https://doi.org/10.1016/S0140-6736(19)30427-1.

34. Nylund KL, Asparouhov T, Muthén BO. Deciding on the number of classes in latent class analysis and growth mixture modeling: a Monte Carlo simulation study. Struct Equation Modeling Multidiplinary J. 2007;14(4):53569. https://doi.org/10.1080/10705510701575396.

35. Kirchberger I, Meisinger C, Heier M, Zimmermann AK, Thorand B, Autenrieth CS, et al. Patterns of multimorbidity in the aged population. Results from the KORA-Age study. PLoS One. 2012;7(1):e30556.

36. Prados-Torres A, Poblador-Plou B, Calderón-Larrañaga A, Gimeno-Feliu LA, González-Rubio F, Poncel-Falcó A, et al. Multimorbidity patterns in primary care: interactions among chronic diseases using factor analysis. PLoS One. 2012;7(2):e32190. https://doi.org/10.1371/journal.pone.0032190.

37. Wang $R$, Yan $Z$, Liang $Y$, Tan EC, Cai C, Jiang $H$, et al. Prevalence and patterns of chronic disease pairs and multimorbidity among older Chinese adults living in a rural area. PLoS One. 2015;10(9):e0138521. https://doi.org/1 0.1371/journal.pone.0138521.

38. Gu J, Chao J, Chen W, Xu H, Wu Z, Chen H, et al. Multimorbidity in the community-dwelling elderly in urban China. Arch Gerontol Geriatr. 2017;68: 62-7. https://doi.org/10.1016/j.archger.2016.09.001.

39. She R, Yan Z, Jiang H, Vetrano DL, Lau JTF, Qiu C. Multimorbidity and healthrelated quality of life in old age: role of functional dependence and depressive symptoms. JAMDA. 2019;20(9):1143-9. https//doi.org/10.1016/j.jamda.2019.02.024.

40. Yao S, Cao G, Han L, Chen Z, Huang Z, Gong P, et al. Prevalence and patterns of multimorbidity in a nationally representative sample of older Chinese: results from the China health and retirement longitudinal study. J Gerontol A Biol Sci Med Sci. 2020;75(10):1974-80. https://doi.org/10.1093/ gerona/glz185.

41. Yao S, Meng X, Cao G, Huang Z, Chen Z, Han L, et al. Associations between multimorbidity and physical performance in older Chinese adults. Int J Environ Res Public Health. 2020;17(12):4546. https://doi.org/10.3390/ijerph17124546.

42. Yao S, Cao G, Li M, Ai P, Huang Z, Xu B. The prevalence and patterns of multimorbidity among community-dwelling older adults in China: a crosssectional study. Lancet. 2018;392(Supplement 1):S84. 
43. Garin N, Olaya B, Perales J, Moneta MV, Miret M, Ayuso-Mateos JL, et al. Multimorbidity patterns in a national representative sample of the Spanish adult population. PLoS One. 2014;9(1):e84794. https://doi.org/10.1371/journa I.pone.0084794.

44. Olaya B, Domènech-Abella J, Moneta MV, Lara E, Caballero FF, Rico-Uribe $L A$, et al. All-cause mortality and multimorbidity in older adults: the role of social support and loneliness. Exp Gerontol. 2017;99:120-6. https://doi.org/1 0.1016/j.exger.2017.10.001.

45. Amell A, Roso-Llorach A, Palomero L, Cuadras D, Galvan-Femenia I, SerraMusach J, et al. Disease networks identify specific conditions and pleiotropy influencing multimorbidity in the general population. Sci Rep. 2018;8(1): 15970. https://doi.org/10.1038/s41598-018-34361-3.

46. Calderon-Larranaga A, Vetrano DL, Ferrucci L, Mercer SW, Marengoni A, Onder G, et al. Multimorbidity and functional impairment-bidirectional interplay, synergistic effects and common pathways. J Intern Med. 2019; 285(3):255-71. https://doi.org/10.1111/joim.12843.

47. Jeon SW, Kim YK. Unresolved issues for utilization of atypical antipsychotics in schizophrenia: antipsychotic Polypharmacy and metabolic syndrome. Int J Mol Sci. 2017;18(10):2174. https://doi.org/10.3390/ijms18102174.

48. Ferdinandy P, Baczko I, Bencsik P, Giricz Z, Gorbe A, Pacher P, et al. Definition of hidden drug cardiotoxicity: paradigm change in cardiac safety testing and its clinical implications. Eur Heart J. 2019;40(22):1771-7. https:// doi.org/10.1093/eurheartj/ehy365.

49. Chen Y, Wang C, Liu Y, Yuan Z, Zhang W, Li X, et al. Incident hypertension and its prediction model in a prospective northern urban Han Chinese cohort study. J Hum Hypertens. 2016;30(12):794-800. https://doi.org/10.1038//hh.2016.23.

50. International Consortium for Blood Pressure Genome-Wide Association S, Ehret GB, Munroe PB, Rice KM, Bochud M, Johnson AD, et al. Genetic variants in novel pathways influence blood pressure and cardiovascular disease risk. Nature. 2011:478(7367):103-9. https://doi.org/10.1038/nature10405.

51. Costantino S, Paneni F, Cosentino F. Ageing, metabolism and cardiovascular disease. J Physiol. 2016;594(8):2061-73. https://doi.org/10.1113/JP270538.

52. He FJ, Macgregor GA. Role of salt intake in prevention of cardiovascular disease: controversies and challenges. Nat Rev Cardiol. 2018;15(6):371-7. https://doi.org/10.1038/s41569-018-0004-1.

53. Santos-Parker JR, LaRocca TJ, Seals DR. Aerobic exercise and other healthy lifestyle factors that influence vascular aging. Adv Physiol Educ. 2014;38(4): 296-307. https://doi.org/10.1152/advan.00088.2014.

\section{Publisher's Note}

Springer Nature remains neutral with regard to jurisdictional claims in published maps and institutional affiliations.

Ready to submit your research? Choose BMC and benefit from:

- fast, convenient online submission

- thorough peer review by experienced researchers in your field

- rapid publication on acceptance

- support for research data, including large and complex data types

- gold Open Access which fosters wider collaboration and increased citations

- maximum visibility for your research: over $100 \mathrm{M}$ website views per year

At $\mathrm{BMC}$, research is always in progress.

Learn more biomedcentral.com/submissions 